\title{
Neural Regulation of Insulin Secretion in the Dog
}

\author{
Daniel Porte, Jr., Lucien Girardier, Josianne Seydoux, \\ Yasunori Kanazawa, and Jean Posternak \\ From the Institute of Clinical Biochemistry and Institute of Physiology, \\ University of Geneva, 1211 Geneva 4 Switzerland, Department of Medicine, \\ University of Washington, and the Veterans Administration Hospital, \\ Seattle, Washington, 98108
}

A B S T R A C T The effects of stimulation of the mixed autonomic nerve to the dog pancreas has been studied under conditions in which both pancreaticoduodenal vein blood flow and insulin concentration were determined. Stimulation resulted in increased insulin output, which was blocked by prior administration of atropine. Blood flow was reduced by stimulation in proportion to the rate of stimulation. At $40 \mathrm{stimuli} / \mathrm{s}$ a maximum effect was found at $1 \mathrm{~min}$ with a gradual return toward base line despite continued application of the stimulus. Atropinization had no effect on blood flow changes. Insulin responses to $0.1 \mathrm{~g} / \mathrm{kg}$ glucose were reduced on the average $40 \%$ by simultaneous stimulation of the pancreatic nerve at $40 \mathrm{cycles} / \mathrm{s}$ in atropinized animals. These studies establish this preparation as a reproducible model for the direct examination of autonomic influences on endocrine pancreatic function. From them it is concluded that the nerve supply to the endocrine pancreas of the dog is sufficient to inhibit insulin secretion by activation of the sympathetic nerves and to stimulate insulin secretion by activation of the parasympathetic nerves.

\section{INTRODUCTION}

Within the past 10 yr by use of electron microscopy and special stains, it has been clear that both parasympathetic and sympathetic nerve endings can be visualized quite close to the hormone-producing cells of the endocrine pancreas (1-3). The conditions under which these neurons might be stimulated to secrete their contained chemical transmitters have never been adequately defined. The demonstration that the known transmitters themselves do

This work was presented in part at the 31st Annual Meeting of the American Diabetes Association, San Francisco, Calif., 22 June 1971 (Diabetes. 20: 340).

Received for publication 16 August 1972 and in revised form 9 October 1972. affect insulin output suggests that if they were to be released, they would be expected to alter insulin secretion directly and influence the islet cell response to other regulators of insulin secretion. Norepinephrine, the sympathetic neurotransmitter, has been found to inhibit insulin release by stimulation of the alpha adrenergic receptor $(4,5)$. Thus it is not surprising that states of increased sympathetic activity such as burns, myocardial infarction and exercise are associated with inhibition of glucosestimulated insulin release $(6-8)$. It is not clear, however, whether this inhibition was due to the direct effect of neural stimulation of the pancreatic nerves or whether this was an indirect effect of elevated levels of circulating epinephrine and norepinephrine released from non-pancreatic nerve endings and the adrenal medulla.

There is also evidence that the parasympathetic system regulates insulin output. Acetylcholine or its analogues have been found to increase insulin release both in vitro and in vivo $(4,9)$. Stimulation of the parasympathetic vagus nerve has been shown to release insulin $(10,11)$. A parasympathetic vagal mechanism is also probably responsible for the increased insulin secretion and hypoglycemia induced by neural conditioning procedures $(12,13)$ since it is blocked by vagotomy or atropine (14). However, it is possible that the vagal stimulation and conditioning experiments increase insulin by an indirect rather than a direct mechanism since these neural inputs might release one or another of the gastrointestinal factors which in turn stimulate insulin release (15).

Therefore, in the present study we have attempted to clarify further the question of direct neural control for the endocrine pancreas. Dogs were studied in whom pancreatic perivascular nerves were isolated, cut, and stimulated under circumstances where pancreaticoduodenal insulin levels and pancreatic blood flow could be measured simultaneously. 


\section{METHODS}

All dogs weighed $15 \mathrm{~kg}$ or more and were studied after an overnight fast under anesthesia of pentobarbital and succinylcholine. After tracheostomy, ventilation was regulated to maintain blood $\mathrm{pH}$ within the range $7.35-7.45$ by the addition of systemic bicarbonate or alteration of ventilation parameters based upon simultaneously measured $\mathrm{pH}, \mathrm{PCO}_{2}$ and $\mathrm{Po}_{2}$. An electric heating blanket was adjusted manually to maintain rectal temperature between $37.5-39.5^{\circ} \mathrm{C}$ because we noticed in our initial experiments that body temperature rapidly drops in nonheated dogs under these experimental conditions. In order to be able to measure pancreatic insulin output, laparotomy was performed and an extracorporeal pancreatic blood circuit was made using a modification of the method of Kanazawa, Kuzuya, and Ide (16). First, the inferior pancreaticoduodenal vein was tied and cannulated by a small polyethylene cannula. It was infused with heparin at a rate of $40 \mathrm{U} / \mathrm{min}$ in a small volume to anticoagulate effluent pancreatic venous blood before its entry into an extracorporeal circuit which was prepared by cannulating the superior pancreaticoduodenal vein. This larger cannula of teflon and Silastic returned its flow into the portal vein through another Teflon cannula held in place by a pure-string suture. Under these conditions, approximately one-third to one-half of the pancreatic body has a blood flow via the cannulated superior pancreaticoduodenal vein and the extracorporeal circuit, while the remaining one-half to two-third of the pancreas drains through the splenic and/or mesenteric veins into the portal vein by a separate circuit. Flow was measured by collecting timed blood samples after interruption of the extracorporeal circuit and adjusting back pressure in the catheter to portal venous pressure using the distal catheter as a manometer. The pancreatic nerves were isolated along the course of the superior pancreaticoduodenal artery just before their entrance into the pancreatic substance. They usually coursed as one group of several large nerve bundles inferior and medial to the artery and another group contained within the loose connective tissue surrounding this artery. Therefore, the artery was stripped of its outer connective tissue containing nerves and both these nerves and the nerves running more medial and inferior to the artery were cut and tied and then placed in a stimulating silver chloride electrode. Stimulation of the isolated cut nerves was performed with a constant current stimulator using pulses of $10 \mathrm{~mA}$ and

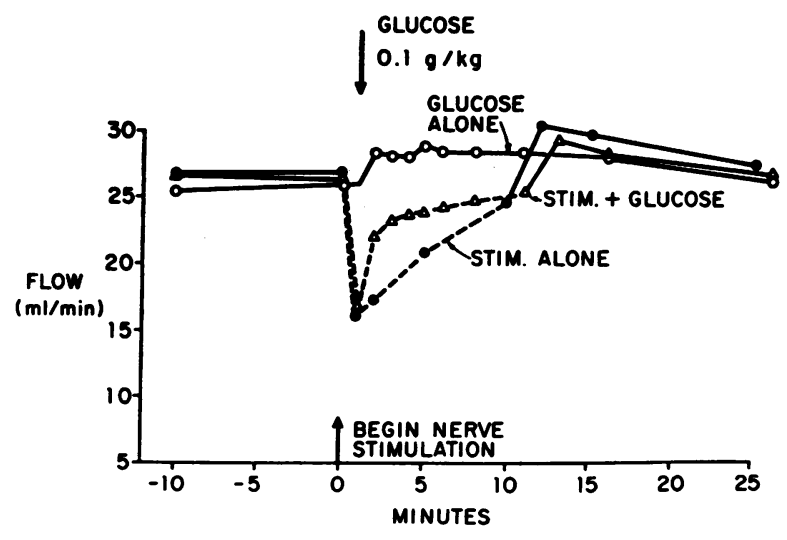

FIgURE 1 The effect of neural stimulation $40 / \mathrm{s}$ and glucose on pancreaticoduodenal blood flow. Stimulation period indicated by dashed lines.

1 ms duration. The voltage drop across the electrode was monitored and remained nearly constant throughout each experiment. Electrode resistance varied between experiments from 900 to $3000 \Omega$. Immunoreactive insulin was measured on heparinized plasma by a conventional double-antibody radioimmunoassay using porcine insulin as standard (17). Plasma glucose was estimated by a glucose oxidase method (18).

\section{RESULTS}

Stimulation generally resulted in a decrease in blood flow, but the pattern depended on the rate of stimulation and whether or not it was associated with glucose administration. Up to approximately 5 stimuli/s blood flow was depressed at $1 \mathrm{~min} 10-20 \%$ and remained decreased for the entire $10 \mathrm{~min}$. With higher stimulation rates, the initial drop was larger but flow returned to the control value by $10 \mathrm{~min}$ despite the continuous application of the stimulus. At $100 \mathrm{stimuli} / \mathrm{s}$ a maximal initial effect was noted with an $80 \%$ reduction in flow

TABLE I

The Effects of Neural Stimulation and Glucose on Pancreaticoduodenal Blood Flow (ml/min)

\begin{tabular}{|c|c|c|c|c|c|c|}
\hline Dog no. & $\begin{array}{l}\text { Control } \\
\text { prestim. }\end{array}$ & $\begin{array}{l}\text { Stimulation } \\
\text { mean flow } \\
1-10\end{array}$ & $\begin{array}{c}\text { Control } \\
\text { preglucose }\end{array}$ & $\begin{array}{c}\text { Mean flow } \\
\text { glucose } \\
1-10\end{array}$ & $\begin{array}{l}\text { Control } \\
\text { prestim. }\end{array}$ & $\begin{array}{c}\text { Mean flow } \\
\text { stim }+ \text { glucose } \\
1-10\end{array}$ \\
\hline 1 & 31.8 & 30.6 & 28.2 & 31.2 & 24.0 & 22.4 \\
\hline 2 & 23.4 & 22.3 & 24.6 & 23.7 & 17.4 & 16.7 \\
\hline 3 & 18.0 & 15.5 & 20.4 & 21.7 & 18.6 & 16.9 \\
\hline 4 & 24.9 & 23.7 & 24.9 & 27.1 & 33.0 & 29.8 \\
\hline 5 & 53.4 & 39.3 & 50.4 & 53.9 & 52.8 & 49.1 \\
\hline 6 & 28.8 & 14.9 & 25.8 & 27.4 & 31.8 & 27.2 \\
\hline 7 & 13.8 & 11.6 & 12.0 & 13.3 & 13.8 & 15.9 \\
\hline 8 & 20.4 & 9.7 & 19.4 & 21.8 & 20.4 & 15.9 \\
\hline Mean & 26.8 & 20.9 & 25.7 & 27.5 & 26.5 & 24.3 \\
\hline SD & 12.3 & 10.1 & 11.1 & 11.9 & 12.6 & 11.4 \\
\hline$P$ & \multicolumn{2}{|c|}{$<0.05$} & \multicolumn{2}{|c|}{$<0.01$} & \multicolumn{2}{|c|}{$<0.05$} \\
\hline
\end{tabular}




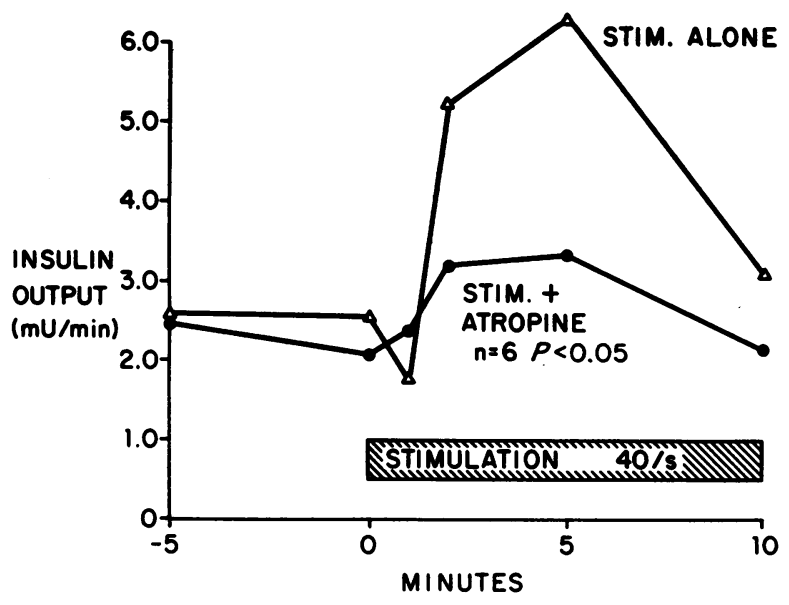

FIGURE 2 The effect of nerve stimulation on insulin output before and after atropine. The mean integrated insulin output during the $10 \mathrm{~min}$ postatropine stimulation of 2.76 $\pm 0.73 \mathrm{mU} / \mathrm{min}$ (SEM) was significantly less than the mean output without atropine of $4.51 \pm 1.06 \mathrm{mU} / \mathrm{min}$ by paired statistical analysis.

at $1 \mathrm{~min}$ and return to control at $5 \mathrm{~min}$. Thus higher stimulation rates reduced blood flow more at $1 \mathrm{~min}$ but were associated with a more rapid return to control flow rates during stimulation. In most instances when the stimulus was stopped there was a rebound hyperemia which lasted from 10 to $25 \mathrm{~min}$ whether or not blood flow had returned to control before the cessation of stimulation or not. These findings are illustrated in eight paired dog studies at 40 stimuli/s in Fig. 1 and details of the data are given in Table I. When glucose was given alone to these same animals there was a small, but significant $(P<0.01)$ increase in flow from the 1st to the 7 th $\mathrm{min}$. When $0.1 \mathrm{~g} / \mathrm{kg}$ glucose was rapidly infused after $1 \mathrm{~min}$ of neural stimulation, the effects of glucose to increase flow partly offset the tendency of stimulation to decrease flow. Thus although the $1 \mathrm{~min}$ stimulation preglucose decrease in flow was similar and significantly lower than glucose alone, both the 1st $(P<$ $0.05)$ and 4th $(P<0.1)$ min flows after glucose and stimulation were less than the decrease observed with stimulation alone (Fig. 1). Atropinization did not alter these blood flow patterns.

Despite the reduction in flow, stimulation at $40 / \mathrm{s}$ when applied alone usually resulted in a small immediate increase in insulin output. This increment peaked between 2-5 min and returned to near base line despite continued stimulation for $10 \mathrm{~min}$. In the six paired studies shown in Fig. 2 this integrated $10 \mathrm{~min}$ increase was significantly reduced $(P<0.05)$ by atropine pretreatment $(1.0 \mathrm{mg} / 15 \mathrm{~kg}$ intravenously $10-20 \mathrm{~min}$ before the second stimulation), and was therefore ascribed to parasympathetic stimulation.
To study the effects of relatively pure sympathetic stimulation, similar atropine pretreatment was given to all subsequently studied animals. In those given stimulation and glucose last an additional $0.5 \mathrm{mg} / 15 \mathrm{~kg}$ was given intravenously 10-20 min before the stimulation. In these studies glucose was used to induce insulin release since it had previously been found that the effects of exogenous catecholamines on insulin secretion are most easily detected during the acute insulin response to glucose (19).

As shown in Figs. 3 and 4, insulin output in response to $0.1 \mathrm{~g} / \mathrm{kg}$ glucose pulse intravenously was reduced in eight of nine dogs when the challenge was preceded by $1 \mathrm{~min}$ of stimulation at $40 \mathrm{cycles} / \mathrm{s}$ and continuation of the stimulation for another $10 \mathrm{~min}$. The depression of the insulin response occurred whether the control glucose pulse was given before $(n=4)$ or after $(n=5)$ the experimental glucose pulse and nerve stimulation $(P<$ $0.05)$. The total insulin release over $10 \mathrm{~min}$ was calculated by integration of the area under the $0-10 \mathrm{~min}$ response curve since virtually all of the insulin released from the pancreas by glucose was completed by $10 \mathrm{~min}$. The mean decrease was $40 \%$ and ranged from $25-75 \%$. In three other studies, 5 stimuli/s was compared with 40 simuli/s. Although the slower rate of stimulation was associated with lesser effects on blood flow, the inhibition of pancreatic insulin output by nerve stimulation appeared to be similar (Fig. 4).

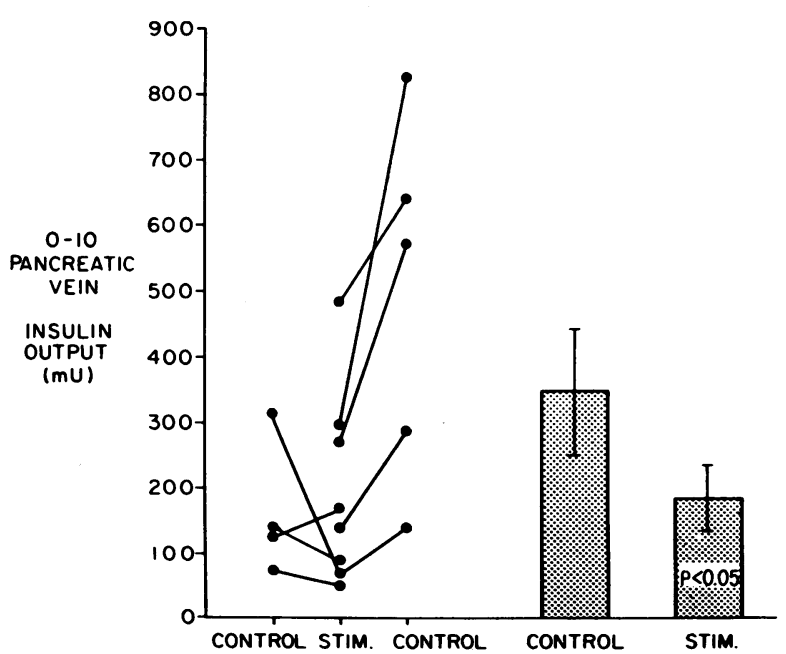

FIGURE 3 The effects of neural stimulation $40 / \mathrm{s}$ for 11 min on the integrated pancreaticoduodenal vein insulin output to glucose in nine atropinized dogs. Glucose given after $1 \mathrm{~min}$ of stimulation. Four dogs were given glucose alone first, and five dogs glucose alone after neural stimulation and glucose. Mean data \pm SEM shown on the right. $P<0.05$ by paired comparison. 


\section{DISCUSSION}

These studies indicate a direct effect of neural input upon insulin secretion. Since there are definite flow changes associated with mixed nerve stimulation it is important to measure total insulin output rather than concentration when evaluating neural effects at the pancreatic level. Nevertheless, the regulatory effect of nerve stimulation via alterations in pancreatic blood flow was considered unlikely to be the sole explanation for either the parasympathetic increase or the sympathetic decrease in pancreatic insulin output observed. In the case of sympathetic inhibition the magnitude of the blood flow change induced by nerve stimulation at $40 / \mathrm{s}$ when glucose is given is small (Fig. 1, Table I) when compared with the effects of stimulation on insulin output (Fig. 3). The glucose pulse, as noted, diminished the effect of stimulation upon flow so that a flow effect could, at best, account for a decrease of insulin output of the order of $15 \%$. Furthermore, the stimulation at $5 / \mathrm{s}$ was just as effective as $40 / \mathrm{s}$ despite much lesser effects on blood flow. Finally, as shown in Fig. 2, there was a net increase in insulin output both total and minute-tominute resulting from stimulation alone in the nonatropinized animals in the face of a clearcut, initial de-

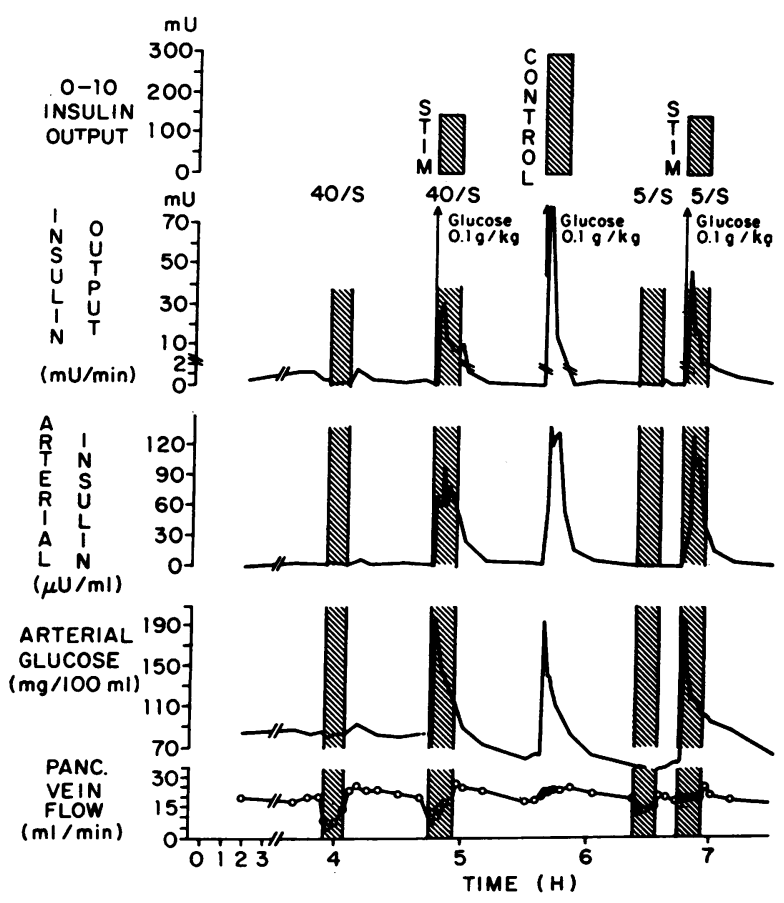

FIgURE 4 A comparison of the effect of 5 stimuli/s with $40 \mathrm{stimuli} / \mathrm{s}$ on basal and glucose-stimulated insulin release in an atropine pretreated dog. This study demonstrates a typical protocol for the experiments in Figs. 1-3. presson of blood flow, indicating that adequate perfusion of responsive pancreatic islets persists during nerve stimulation. Thus, neither the increase nor the decrease in insulin output appears to be related to blood flow. This conclusion is consistent with the known effects of catecholamines and acetylcholine in vitro (4) and reports that pancreatic blood flow is not a critical determinant of pancreatic insulin secretion in the dog (20).

Although not shown here in detail, it should be mentioned that the effect of nerve stimulation upon the insulin output response to glucose was less when evaluated on the basis of arterial insulin concentration alone, rather than in terms of pancreaticoduodenal vein insulin output. This observation is hardly surprising, however, since the systemic administration of glucose stimulates the whole of the pancreas, whereas the direct nerve stimulation used affected only that part of the pancreas for which the flow and pancreatic venous insulin measurements were made. Also, a rather large proportion of the pancreaticoduodenal vein was used for chemical and flow measurements during the crucial first $10 \mathrm{~min}$ after glucose administration, the samples being obtained at intervals of $1 \mathrm{~min}$.

In conclusion, therefore, the findings described here demonstrate that direct nervous stimulation of the pancreatic nerves can increase insulin output via the parasympathetic system and can decrease insulin output via the sympathetic system. They provide support for inferences previously derived from studies of the effects of exogenously administered autonomic transmitters and greatly increase the probability that autonomic transmitters released directly from pancreatic nerve endings do play a role in the physiologic control of insulin producing beta cells. Of course, the present studies do not as yet elaborate the circumstances under which autonomic nerves may in fact be stimulated under physiologic conditions. However, the demonstration of the direct neural responses shown here suggests that specific neural effects must be seriously considered as the possible mediating mechanim in the several physiologic states in which modulation of insulin secretion has been attributed to the functional state of the autonomic nervous system $(6-8,12-14)$. The mechanism envisaged would be more specific than the simple occurrence of a general autonomic discharge or the release of catecholamines from the adrenal medulla.

It should further be mentioned that, in keeping with the known autonomic innervation of both $\mathrm{A}$ and $\mathrm{B}$ cells of the islets of Langerhans (1-3), further analysis of the present studies indicates that the output of pancreatic glucagon is also sensitive to nerve stimulation and is reciprocal to the insulin responses reported here (21). 


\section{ACKNOWLEDGMENTS}

Supported in part by Grant 3.371.70 from the Fonds National Swisse de la Recherche Scientifique and Grants AM8865 and 12829 from the National Institutes of Health.

We thank Jeffrey Porte and Frédéric Renold for technical assistance, Dr. E. B. Marliss for reviewing the manuscript and Professor A. E. Renold for his encouragement.

\section{REFERENCES}

1. Watari, N. 1968. Fine structure of nervous elements in the pancreas of some vertebrates. Z. Zellforsch. Microsk. Anat. 85: 291

2. Orci, L., D. Cameron, A. E. Lambert, Y. Kanazawa, M. Amherdt, and W. Stauffacher. 1970. The autonomous nervous system and the $\beta$-cell; metabolic and morphological observations made in spiny mice (Acomys Cahirinus) and in cultured fetal rat pancreas. Acta Diabetol. Lat. 7 (Suppl. 1) : 184.

3. Esterhuizen, A. C., T. L. B. Spriggs, and J. D. Lever. 1968. Nature of islet-cell innervation in the cat pancreas. Diabetes. $17: 33$

4. Malaisse, W., F. Malaisse-Lagae, P. H. Wright, and J. Ashmore. 1967. Effects of adrenergic and cholinergic agents upon insulin secretion in vitro. Endocrinology. $80: 975$.

5. Porte, D., Jr. 1967. A receptor mechanism for the inhibition of insulin release by epinephrine in man. $J$. Clin. Invest. 46: 86.

6. Porte, D., Jr. 1969. Sympathetic regulation of insulin secretion. Its relation to diabetes mellitus. Arch. Intern. Med. $123: 252$.

7. Taylor, S. H., and P. A. Majid. 1971. Insulin and the heart. J. Mol. Cell Cardiol. 2 : 293.

8. Allison, S. P., P. Hinton, and M. J. Chamberlain. 1968. Intravenous glucose-tolerance, insulin, and free-fattyacid levels in burned patients. Lancet. 2: 1113.

9. Kajinuma, H., A. Kaneto, T. Kuzuya, and K. Nakao. 1968. Effects of methacholine on insulin secretion in man. J. Clin. Endocrinol. Metab. 28: 1384.
10. Frohman, L. A., E. Z. Ezdinli, and R. Javid. 1967. Effect of vagotomy and vagal stimulation on insulin secretion. Diabetes. 16: 443.

11. Kaneto, A., K. Kosaka, and K. Nakao. 1967. Effects of stimulation of the vagus nerve on insulin secretion. Endocrinology. $80: 530$.

12. Woods, S. C., R. A. Hutton, and W. Makous. 1970. Conditioned insulin secretion in the albino rat. Proc. Soc. Exp. Biol. Med. 133: 964.

13. Woods, S. C., K. R. Alexander, and D. Porte, Jr. 1972. Conditioned insulin secretion and hypoglycemia following repeated injections of tolbutamide in rats. Endocrinology. 90: 227.

14. Woods, S. C. 1972. Conditioned hypoglycemia : Effect of vagotomy and pharmacological blockade. Am. J. Physiol. In press.

15. Dupré, J. 1970. Regulation of the secretions of the pancreas. Annu. Rev. Med. 21: 299.

16. Kanazawa, Y., T. Kuzuya, and T. Ide. 1968. Insulin output via the pancreatic vein and plasma insulin response to glucose in dogs. Am. J. Physiol. 215: 620.

17. Morgan, C. R., and A. Lazarow. 1963. Immunoassay of insulin; two antibody system. Plasma insulin levels of normal, subdiabetic, and diabetic rats. Diabetes. 12: 115.

18. Huggett, A. St.G., and D. A. Nixon. 1957. Use of glucose oxidase, peroxidase and o-dianisidine in determination of blood and urine glucose. Lancet. 1: 386.

19. Lerner, R. L., and Porte, D., Jr. 1971. Epinephrine: selective inhibition of the acute insulin response to glucose. J. Clin. Invest. 50: 2453.

20. Rappaport, A. M., T. Kawamura, J. K. Davidson, B. J. Lin, S. Ohira, M. Zeigler, J. A. Coddling, J. Hendersen, and R. E. Haist. 1971. Effects of hormones and of blood flow on insulin output of isolated pancreas in situ. $A m$. J. Physiol. 221 : 343.

21. Porte, D., Jr., E. B. Marliss, L. Girardier, J. Seydoux, Y. Kanazawa, A. E. Renold, and J. Posternak. 1972. Neural regulation of pancreatic glucagon secretion. $J$. Clin. Invest. 51 : 75a. (Abstr.) 